\title{
Perceived Stress among Medical Students: Prevalence, Source and Severity
}

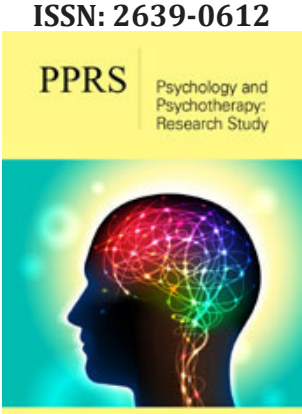

*Corresponding author: Samina Rafique, Chief Medical Officer, Pakistan

Submission: 悳 March 20, 2019

Published: 侮 May 22, 2019

Volume 2 - Issue 3

How to cite this article: Samina R, Zainab W, Fatima S. Perceived Stress among Medical Students: Prevalence, Source and Severity. Psychol Psychother Res Stud. 2(3).PPRS.000538.2019.

DOI: 10.31031/PPRS.2019.02.000538

Copyright@ Samina Rafique, This article is distributed under the terms of the Creative Commons Attribution 4.0 International License, which permits unrestricted use and redistribution provided that the original author and source are credited.

\author{
Samina Rafiquea ${ }^{1 *}$, Zainab Waseem $b^{2}$ and Fatima Sheerinc ${ }^{3}$ \\ ${ }^{1}$ Chief Medical Officer, Pakistan \\ ${ }^{2}$ House Officer, Pakistan \\ ${ }^{3}$ Post graduate trainee, Pakistan
}

\begin{abstract}
Background: Many studies have reported elevated level of stress among medical students which may harm physical as well as psychological health of the students but there is dearth of studies on this topic from Pakistan.
\end{abstract}

Objective: To (a) determine the incidence of stress among undergraduate medical students (b) identify the source of psychological distress and (c) explore the association of perceived stress with socio demographic characteristics and academic grades.

Methods: A cross sectional study was carried out in a public sector medical university which conducts a five year undergraduate medical course. Students from all the five years were recruited by non probability convenient sampling method. Kessler10 psychological distress scale was applied to measure the level of perceived stress as none, mild, moderate, and severe. Prevalence and relation of stress with study variables, (gender, hostel residence, academic year, and academic grades) was studied. Medical Students Stress Questionnaire (MSSQ) short form was used to identify the source of stress.

Results: A total of 261 out of 306 students responded with a response rate of $87 \%$. The overall prevalence of stress was $51.5 \%$, with maximum incidence among students of final year. Male gender, hostel residence and poor academic grades were proved to have significant association with the outcome variable of stress. Students identified three groups of stressors which had a high impact on the psychology of the students. These included academic related stresses, stress associated with witnessing negative patient outcome and distress related to non supportive behavior of the teacher.

Conclusion: More than half of the students were found to be under psychological distress, preventive mental health services, therefore, should be made an essential part of regular clinical services for medical students.

Keywords: Medical education, Stress, academic stressors.

\section{Introduction}

Medical students have to study and master an enormous amount of knowledge and skills. They have to achieve and maintain good academic results in a highly competitive environment, so they have to sacrifice personal and social life which puts them under a lot of stress [1].

Undergraduate medical students have been the most distraught group of students. Worldwide, different studies involving medical students found that occurrence of emotional disorders was higher than that in the general population [2] or any other course undergraduates $[3,4]$. Some amount of stress, which motivates the students and promotes and encourages learning, is desired in medical training but excess stress has adverse consequences which may cause a harmful effect not only on the academic performance [5] but on physical as well as psychological well-being of the student and may lead to the depression and anxiety [6] and even suicidal thoughts $[7,8]$.

Medical students stress can be divided into educational and non-educational related stress. Academics are fundamental part of a student's life and without a positive attitude towards academic objective, students can be besieged with crippling spells of stress. Studies from different parts of the word have shown that academic pressures of high-volume syllabus, 
test taking, and time management are a significant source of stress for students and dominate over other causes of tension among medical students $[9,10]$. A thorough review of the literature reveals that mistreatment of medical students is also prevalent [11] and behavior of the teacher (lack of feedback, uncertainty of what is expected and intimidation by the teacher) has a great impact on student's psyche [12]. Observing humane suffering can be stressful to any individual and medical students are no exceptions [13]. But to the best of our knowledge, these factors have been never addressed in studies from Pakistan. Distress in medical school has been linked to forthcoming health problems also [14]. It is, therefore, imperative for medical educators to know the source and degree of stress among students.

Objective of the study was to estimate the occurrence and identify the potential causes of stress at various levels of medical education among the students of Nishtar Medical College. This will help to design interventions which will help students to cope with the stress and to adjust to different learning environment at different stages of their training.

\section{Method}

This cross-sectional study was conducted in Nishtar Medical College Multan in February 2017 after three months of start of new classes to counter the stress of exams. All five-year students were included in the study. At 5\% confidence interval and 95\% level of confidence the sample size remained 306. Students were recruited by convenient sampling method after taking informed consent. We used the Kessler10 Psychological Distress scale (K10) developed by Kessler et al. [15]. This is a validated questionnaire with good internal consistency and Cronbach's alpha value of 0.919 . At a cut off score of $24, \mathrm{~K} 10$ has a sensitivity of $0.72 \%$ specificity of $0.77 \%$, positive predictive value of 0.53 and a negative predictive value of $0.89 \%$. Many studies [16,17] found it better than GHQ and K6 scales for screening of mental health It comprises of 10 questions which inquire about the frequency of precise symptoms during the last month such as 'tired out for no good reason', 'nervous', and 'sad or depressed. Five possible answers for each question range from 'never' to 'all of the time' were scored from 1 to 5 respectively. Total score obtained was interpreted as follows: A Score of $<20$ means no

Table 1: Stress among study subjects in relation to different study variables. stress, score of 20-24 indicates mild stress, 25-29 moderate stress, and a score of 30-50 represents severe stress [18].

Source of stress was identified by using medical student stress questionnaire (MSSQ) [19]. The items on short form of MSSQ signify 20 events that could be potential sources of stress in medical students. It included academic related stressors, teacher related stressors, and desire and interpersonal related stressors. Response for each event was collected on a 5-point likert scale, ranging from no stress through mild, moderate, high to severe stress. The MSSQ is scored by assigning a value of zero to four for each of the respective responses. In order to test the validity and reliability of the short form, the instrument was piloted to 52 newly graduated medical students. From the pilot data, we calculated Cronbach's alpha value for MSSQ to be 0.95 . In statistical analysis data was cleaned and described as percentages and average and analysed by chi-square test using SPSS version 20.

\section{Results}

Out of 306 questionnaires, 261 were completed and returned with a response rate of $87 \%$. Seven forms were rejected due to deficient information and finally 254 complete survey forms were selected for final analysis.

Mean age of respondents was $20.3+2.4$ years with $63.7 \%$ females ( $n=162)$ and $36.2 \%$ males $(n=92)$. Average stress scores on K10 scale remained 23.2 amongst male and 20.79 amid female students. Overall incidence of stress in study population remained 51.5\% ( $\mathrm{n}=131)$. Among these, 49 (37.4\%) had severe $36(27.4 \%)$ perceived moderate while 44 (35.1\%) had mild level of stress. Demographic profiles of study subjects and prevalence of stress with relation to gender, hostel residence, academic grades and year of study is presented in table 1 , which shows that more males $(61.9 \%, n=57)$ than female study contributors $(45 \%, n=73)$ and more boarders than those residing at home, reported psychological distress. Difference was found to be significant statistically. ( $p$ value $<0.05$ and $<0.001$ respectively). A noteworthy association was observed between stress level and academic achievements. Among high achievers $34.2 \%$ while $44.4 \%$ of those having poor grades were under severe mental stress. The difference remained significant statistically. (Chi-square $=46.07$, $p$ value $<0.001$ ).

\begin{tabular}{|c|c|c|c|c|c|c|}
\hline \multicolumn{7}{|c|}{ Stress } \\
\hline Gender & No Stress & Mild Stress & Moderate Stress & Severe Stress & Total & \\
\hline Male & $37(40.2)$ & $19(20.6)$ & $12(13)$ & $25(27.17)$ & $92(36.2)$ & $\mathrm{P}$ value $<.05$ \\
\hline Female & $79(48.7)$ & $36(22.22)$ & $18(11.1)$ & $29(17.9)$ & $162(63.7)$ & \\
\hline \multicolumn{7}{|l|}{ Residence } \\
\hline Hostel & 54 & 20 & 28 & 38 & 140 & $\mathrm{P}$ value $<0.001$ \\
\hline Home & 69 & 26 & 8 & 11 & 114 & \\
\hline \multicolumn{7}{|l|}{ Grades } \\
\hline Excellent & $38(54.2)$ & $2(2.8)$ & $6(8.5)$ & $24(34.2)$ & 70 & \\
\hline Very good & $47(57.3)$ & $12(14.6)$ & $11(13.4)$ & $12(14.6)$ & 82 & \\
\hline
\end{tabular}




\begin{tabular}{|c|c|c|c|c|c|c|}
\hline Good & $35(37.6)$ & $31(33.3)$ & $18(19.3)$ & $9(9.6)$ & 93 & P value $<0.001$ \\
\hline Poor & $3(33.3)$ & $1(11.1)$ & $1(11.1)$ & $4(44.4)$ & 9 \\
\hline Study Year & & & & & \\
\hline $1^{\text {st }}$ year & $21(46.6)$ & $6(13.3)$ & $6(13.3)$ & $12(26.6)$ & 45 & P value $<0.05$ \\
\hline $2^{\text {nd }}$ year & $26(43.3)$ & $11(18.3)$ & $4(6.6)$ & $8(14.5)$ & $5(9)$ & 55 \\
\hline $3^{\text {rd }}$ year & $26(47.2)$ & $16(29)$ & $11(25.5)$ & $1(2.3)$ & 43 & 50 \\
\hline $4^{\text {th }}$ year & $30(69.7)$ & $10(19.6)$ & $7(13.7)$ & $12(23.5)$ & 51 \\
\hline $5^{\text {th }}$ year & $22(43.1)$ & & & \\
\hline
\end{tabular}

According to our results students of various years' experience different levels of mental tension. We encountered high percentage of psychological distress (53.3\%) in $1^{\text {st }}$ year students which increased in $2^{\text {nd }}$ year and $3^{\text {rd }}$ year ( $56.6 \%$ and $56.3 \%$ respectively). The frequency of stress decreased in $4^{\text {th }}$ year $(29.5 \%)$ but again increased to $56.8 \%$ in final year students. The correlation was found to be significant statistically. $(\mathrm{R}=-0.1518$, $\mathrm{p}$ value $<.05)$.

Main source of stress as described by the student was related to studies (large course content (94.6\%) and lack of time to revise (86.5\%)) followed by patient related stressors such as facing illness or death of the patient (80\%) and talking to patients about personal problems $(68 \%)$. Teacher related stressors such as uncertainty of what is expected (76.7\%), lack of recognition of work done (64.5\%) and verbal or physical abuse by the teacher (55.9\%) were also prominent. Personal related stress as feeling of incompetence and parental wish to study medicine also accounted for stress in $66 \%$ and $59 \%$ of the participants respectively (Figure 1).

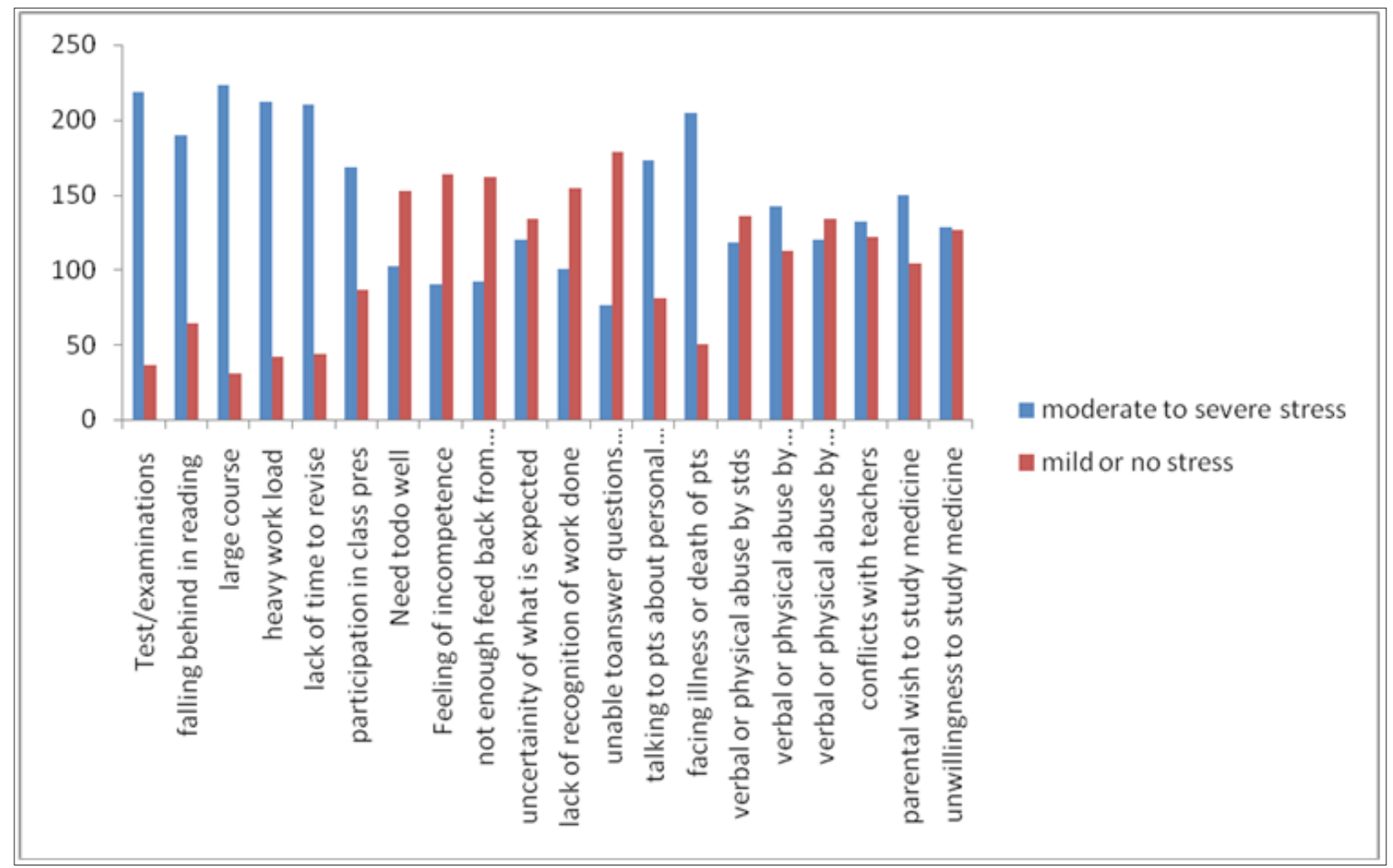

Figure 1: Source of stress among the students of Nishtar Medical University.

\section{Discussion}

Some level of stress is inevitable in advance academic training [20]. As medical education is very tough, only those who have outstanding academic grades can be successful in the course. Therefore, medical students are known to be under more stress as compared to students in other programs [3,4,21]. We found $51.5 \%$ of the students were under stress, while Jadoon et al. [22] reported somewhat lower level (43.89\%) of psychological distress from the same center. Similarly, in a multicenter study, reported that $45.5 \%$ of students suffered from anxiety and depression [23]. Two other studies from Pakistan found higher occurrence (60-70\%) of psychological morbidity [24,25].

Results from other Asian countries show similar or higher prevalence of mental tension such as Bangla Daish and Saudi Arabia respectively [26,27]. While studies from western countries show considerably lower level of psychological distress $[2,4,6,7]$ which 
might be due to great differences in learning atmosphere, syllabus and evaluation methods. Moreover, use of different instrument may also be a contributor to these variations.

We find a significant association between presence of stress and four study variables i.e. gender, academic grades, year in medical school and hostel residence. Higher level of psychological morbidity in male students is in accordance with a previous study conducted in Karachi Pakistan which showed that female gender was actually a protective factor against psychological distress [25]. While other studies from Pakistan as well as abroad reported higher prevalence of depression and anxiety among females [2,20-24,26,27]. Increased frequency of distress in males in our study may be due to smaller sample size but it can also be explained in Pakistani perspective. Despite the stressful training and achievements of high academic merit, doctors have limited opportunities for job and for post-graduation training with inadequate salaries.

As per previous, [28] our results show that medical students remain stressed throughout their training in medical school. There were certain variations in the prevalence of perceived mental tension during different years which can be explained. The high scores obtained by the first- and second-year students in our survey, could be the effect of the hard competition they faced to enter to the medical schools and also due to the process of adjustment in a new and stressful environment as observed in previous studies $[22,23,25]$. On the other hand, $3^{\text {rd }}$ year students must adjust to the hospital setting as well as undergo clinical examinations which were different from year 1and 2. Transition from basic science teaching to clinical teaching has been recognized as a critical phase in the training of medical students [29,30]. Reduction in the level of stress among 4th year students is probably due to comparatively relaxed schedule of wards in this year and students find more time to spend with family and friends as compared to previous years. Same was observed by in a study about the learning environment of medical schools from USA and Canada [29]. Whereas, final year student faces high expectations to become competent doctors and strive to acquire high professional skills $[8,30]$.

Major stressors identified by our respondents were vastness of syllabus and frequency of examinations. This is in line with the previous studies from other countries $[4,7,8]$ as well as from Pakistan [12]. Teacher related stresses such as not enough feedback from the teacher (66\%) physical or verbal abuse (55\%) and conflict (51\%) also contributed towards higher level of distress. This is particularly important as student feel embarrassed and disgraced in response to being intimidated by their teachers and may lose confidence in them [10]. Facing death of the patient was another main cause of stress among $80 \%$ students. Death of the patient always leaves a powerful impact on psyche of the doctors and students. Angoff [13] noticed that $73.1 \%$ of the students cried in response to patients' death during clinical rotation. To the best of our knowledge, no study about the stress of medical students from Pakistan, considered this point.

From the list of comparatively high-impact stressors, we discover three useful groups of stressors for future exploration: those associated with syllabus and assessment processes those associate with the distress of witnessing negative patient outcomes and those related to behavior of teacher. Hence, outcome of this study will be helpful to identify the range of stressors that have a strong effect on medical students.

\section{Conclusion}

These finding of our study indicate towards the need for launching counseling and preventive mental health services in medical institutions which will help students make smooth adjustments in various learning environments with varying learning demands and a rising burden on their mental and physical capability. It might be successful in managing and thereby controlling the negative consequences of psychological distress in medical students [31]. Several developed countries have emphasized the importance of such programs for example accreditation standards for the Association of American medical colleges require that "Each school must have....programs to promote mental health of the students and facilitate their adjustment to the physical and emotional demands of a medical school" [32]. Faculty development programs are also beneficial as they have a positive impact on behavior and attitude of the teacher [33] and hence can manage this important stressor.

\section{Limitations}

There are certain limitations to our study. As the study was carried out in a public sector medical school, the results may be applied to other similar institutions as criteria for admission, schedules and syllabi are alike in all public sector medical institutions. But the conditions may be different in private medical colleges. Moreover, a longitudinal study is needed to explore the long-term effects of stress on young doctors.

\section{References}

1. Salam A, Yusuf R, Bakar SMA, Haque M (2013) Stress among medical students in Malaysia: A systematic review of literature. International Medical Journal 20(6): 649-655.

2. Dyrbye LN, Thomas MR, Shanafelt TD (2006) Systematic review of depression, anxiety and other indicators of psychological distress among US and Canadian medical students. Acad Med 81(4): 354-373.

3. Jafri SAM, Zaidi E, Aamir IS, Aziz HW, Din I, et al. (2017) Stress level comparison of medical and non-medical students: A cross sectional study done at various professional colleges in Karachi, Pakistan. Acta Psychopathol 3: 2.

4. Honney K, Buszewicz M, Coppola W, Griffin M (2010) Comparison of levels of depression in medical and non-medical students. Clin Teach $7(3): 180-184$.

5. Sohail N (2013) Stress and academic performance among medical students. J Col Phy Surg Pak 23(1): 67-71.

6. Shah M, Hasan S, Malik S, Sreeramareddy CT (2010) Perceived stress, sources and severity of stress among medical undergraduates in a Pakistani medical school. BMC Med Educ 10: 2.

7. Tyssen R, Vaglum P, Gronvold NT, Ekeberg O (2001) Suicidal ideation among medical students and young physicians: a nationwide and prospective study of prevalence and predictors. J Affeac Disord 64(1): 69-71. 
8. Naseem S, Munaf S (2017) Suicidal ideation, depression, anxiety, stress and life satisfaction of medical, engineering and social science students. J Ayub Med Coll Abbotabad 29(3): 422-427.

9. Saipanish R (2003) Stress among medical students in a Thai medical school. Med Teach 25(5): 502-506.

10. Moffat K, McConnachie A, Ross S, Morrison JM (2004) First year medical student stress and coping in a problem-based learning medical curriculum. Med Educ 38(5): 482-491.

11. Cook AF, Arora VM, Rasinski KA, Curlin FA, Yoon JD (2014) The prevalence of medical student's mistreatment and its association with burnout. Acad Med 89(5): 749-754.

12. Seabrook MA (2004) Intimidation in medical education: student's and teacher's perspectives. Stud High Educ 29(1): 59-74.

13. Angoff NR (2001) Crying in the curriculum. JAMA 286(9): 1017-1018.

14. Tyssen R, Vaglum P, Gronvold NT, Ekeberg $O$ (2001) Factors in medical school that predict postgraduate mental health problems in need of treatment. A nationwide and longitudinal study. Med Educ 35(2): 110120.

15. Kessler RC, Andrews G, Colpe LJ, Hiripi E, Mroczek DK, et al. (2002) Short screening scales to monitor population prevalence and trends in nonspecific psychological distress. Psychol Med 32(6): 959-976.

16. Furukawa TA, Kessler RC, Slade T, Andrews G (2003) The performance of the K6 and K10 screening scales for psychological distress in the Australian national survey of mental health and well-being. Psychol Med 33(2): 357-362.

17. Cornelius BL, Groothoff JW, Van der Klink JJ, Brouwer S (2013) The performance of the K10, K6 and GHQ-12 to screen for present state DSMIV disorders among disability claimants. BMC Public Health 13: 128.

18. Brooks RT, Beard J, Steel Z (2006) Factor structure and interpretation of the K10. Psychol Assess 18(1): 62-70.

19. Yousuff MSB (2011) A confirmatory factor analysis study on the medical student stressor questionnaire among Malaysian medical students. Edu Med J 3(1): 44-53.

20. Stecker T (2004) Well-being in an academic environment. Med Educ 38(5): 465-478.

21. Aktekin M, Karaman T, Senol YY, Erdem S, Erengin H, et al. (2001) Anxiety, depression and stressful life events among medical students: a prospective study in Antalya, Turkey. Med Educ 35(1): 12-17.
22. Jadoon NA, Yaqoob R, Raza A, Shehzad MA, Zeshan SC (2010) Anxiety and depression among medical students: a cross-sectional study. J Pak Med Assoc 60(8): 699-702.

23. Hashmi AM, Aftab MA, Naqvi SH, Sajjad W, Mohsin M, et al. (2014) Anxiety and depression in Pakistani medical students: a multicenter study. Health Med 8(7): 813-820.

24. Inam SN, Saqib A, Alam E (2003) Prevalence of anxiety and depression among medical students of a private university. J Pak Med Assoc 53(2): 44-47.

25. Khan MS, Mahmood S, Badshah A, Ali SU, Jamal Y (2006) Prevalence of depression, anxiety and their associated factors among medical students in Karachi, Pakistan. J Pak Med Assoc 56(12): 583-586.

26. Eva EO, Islam MZ, Mosaddek ASM, Rahman MF, Rozario RJ, et al. (2015) Prevalence of stress among medical students: a comparative study between public and private medical schools in Bangladesh. BMC Res Notes 8: 327.

27. Abdulghani HM, AlKanhal AA, Mahmoud ES, Ponnamperuma GG, Alfaris EA (2011) Stress and its effects on medical students: A cross-sectional study at a college of medicine in Saudi Arabia. J Health Popul Nutr 29(5): 516-522.

28. Niemi PM, Vainiomaki PT (2006) Medical student's distress-quality, continuity and gender differences during a six-year medical program. Med Teach 28(2): 136-141.

29. Dunhama L, Dekhtyara M, Gruenerb G, CichoskiKelly E, Deitz J, et al. (2017) Medical student perception of the learning environment of medical school change as student's transition to clinical training in undergraduate medical school. Teach Learn Med 29(4): 383-391.

30. El-Masry R, Ghreiz MS, Helal M R, Audeh MAT (2013) Perceived stress and burnout among medical students during the clinical period of their education. Ibnosena J Med BS 5(4): 179-188.

31. Rozenzweig S, Reibel KD, Greeson MJ, Brainard CG, Hojat RM (2003) Mindfulness based stress reduction lowers psychological distress in medical students. Teach Learn Med 15(2): 88-92.

32. (2003) Functions and structure of a medical school: Standards for accreditation of medical education programs leading to the MD degree, Liaison Committee on medical education, Washington, USA.

33. Mukhtar F, Chaudhry AM (2015) Faculty development in medical institutions: Where do we stand in Pakistan. J Ayub Med Coll Abbottabad 22(3): 210-213. 